\title{
Assessment of the Prevalence of Malnutrition in Under 5 Aged Children of Slums in Dhaka City, Bangladesh
}

\author{
Md. Aynal Hoque ${ }^{1 *}$, Hossain Sahid Kamrul Alam², Md. Abu Sayeed ${ }^{3}$, A. T. M. Azharul Haque ${ }^{4}$
}

\author{
${ }^{1}$ Associate Professor and Head, Department of Paediatric Rheumatology, Bangladesh Institute of Child Health and Dhaka Shishu \\ (Children) Hospital, Dhaka, Bangladesh \\ ${ }^{2}$ Associate Professor and Head, Department of Adolescent Paediatric, Bangladesh Institute of Child Health and Dhaka Shishu \\ (Children) Hospital, Dhaka, Bangladesh \\ ${ }^{3}$ Assistant Professor, Department of Paediatric Cardiology, Bangladesh Institute of Child Health and Dhaka Shishu (Children) \\ Hospital, Dhaka, Bangladesh \\ ${ }^{4}$ Registrar, Department of Paediatric Rheumatology, Dhaka Shishu (Children) Hospital, Dhaka, Bangladesh
}

DOI: $10.36347 /$ sjams.2021.v09i02.018

| Received: 11.02.2021 | Accepted: 23.02.2021 | Published: 26.02.2021

*Corresponding author: Md. Aynal Hoque

Background: The uncontrollable rapid growth of urban slum population, accompanied by poor nutritional status is a devastating problem. This study was aimed to assess the prevalence of protein energy malnutrition (PEM) in slum areas of Dhaka city. Methodology: This cross sectional study was conducted among 500randomly selected children aged 6 months to 5 years of Agargaon and Beribadh slum of Dhaka city, Bangladesh. After taking consents from parents anthropometric measurements were done using standard methods. These are weight, height, MUAC and age. Data were entered onto a questionnaire and analyzed using SPSS windows 21 programs. Results: Amongst the 500 under 5 aged children male to female ratio was equal (1.08:1). Majority (125) children were 13 months to 24 months aged. According to weight for height Z-score, $16 \%$ of the children had mild to moderate wasting and $07 \%$ had severe wasting. According to height for age Z-score about $36 \%$ of children were stunted (mild/moderate) and $05 \%$ children were severely stunted. About $31 \%$ of children were under weight (mild/moderate) and $04 \%$ children were severely underweight. According to MUAC classification $32 \%$ of children had mild/ moderate malnutrition and $08 \%$ had severe malnutrition. Conclusions: Overall, nutritional status of the under 5 children of slums of Agargaon and Beribadh were below acceptance.

Keywords: Under 5 slum children, Nutritional status, Anthropometry.

Copyright ( $\odot 2021$ The Author(s): This is an open-access article distributed under the terms of the Creative Commons Attribution 4.0 International License (CC BY-NC 4.0) which permits unrestricted use, distribution, and reproduction in any medium for non-commercial use provided the original author and source are credited.

\section{INTRODUCTION}

Human health, disease, productivity, socio economic development, quality of life index etc. are directly related and dependent on nutrition. Malnutrition is a serious public health problem that has been linked to increase risk of morbidity and mortality. Many factors can cause malnutrition, most of which relate to immunization, socio economic condition and repeated infections, particularly in underprivileged population. Overpopulation, too, is a breakdown of the ecological balance in which the population may exceed the carrying of the environment. This then undermines food production, which leads to inadequate food intake and/or the consumption of non-nutritious food and thus to malnutrition. On the other hand, malnutrition itself can have far-reaching impacts on the environment and can induce a cycle leading to additional health problems and deprivation. A good percentage of the population of
Dhaka city is living in the slums [1]. In slum areas of Dhaka city there is a very high prevalence of malnutrition. The prevalence of wasting, stunting and underweight were $23 \%, 41 \%$ and $35 \%$, respectively. The prevalence of malnutrition is average in Dhaka slums than the national average which is $49 \%$ for stunting, $17.5 \%$ for wasting and $56 \%$ for underweight [2]. Malnutrition is increasing rapidly among socioeconomically deprived sectors of the developing countries where poverty, unemployment, illiteracy and ignorance are rampant [3]. It was found that more than a third of the world's children are affected by protein energy malnutrition (PEM), and the highest frequency of the indicators are wasting, stunting, and underweight among which $80 \%$ of the affected children are from Asia [4]. The nutritional problem in Bangladesh is well known where $69 \%$ of children are victim of any form of PEM and 12\% children are severely undernourished [5]. 
Aynal Hoque et al; Sch J App Med Sci, Feb, 2021; 9(2): 267-270

PEM is a major cause for childhood mortality and morbidity in underdeveloped countries. Eighty percent of children below 5 years of age suffer from $2^{\text {nd }}$ and $3^{\text {rd }}$ degree of PEM. PEM may be regarded as a generalized disorder affecting the structure and function of the entire body, biochemical changes like serum total protein, albumin, globulin and iron are invariable accompaniment in PEM [6]. As a large population in slum areas of Dhaka City are children this descriptive cross sectional study was conducted with a view to determine the nutritional status of under five children of Agargaon and Beribadh slums.

\section{Methodology}

This is a descriptive cross sectional study. It was carried out during February-2016 to July-2018 at Agargaon and Beribadh slums of Dhaka city. A total of 500 under-5 aged children constituted the study population. Seriously ill, mentally retarded children and parents unwilling to participate in the study were excluded from the study. Those children living in slum for at least 6 months, age ranged from 06 months to 5 years and parents willing to participate in this study were included. To determine the nutritional status following parameters were studied: (1) Length was determined in 06 months to 2 years of age by infantometer in lying position and height after 2 years up to 5 years in standing position by stadiometer. Technique of height measurement: height was recorded in standing position without footwear, foot together, knees straight and heels, buttocks and shoulder in contact with the vertical wall. The child was held firmly with eyes looking straight up and the body held as straight as possible with the knees pressed straight. The height was measured to the nearest millimeter. (2) Weight: Weight was taken by electronic weighing machine. The child was asked to stand on the weighing machine with minimum clothing and without shoes and any weight in hands or touching or catching other things. Weight was recorded to the nearest grams. (3) Age: Asking with parents or any records. (4) Mid Upper Arm Circumference (MUAC): MUAC is an easy and useful measurement. It was recorded by measuring tape. The middle of the left arm was detected by the midpoint of a line between the tip of the acromion process of scapula and olecranon process of ulna. Then at the midpoint the measuring tape was wrapped round gently but firmly avoiding compression of soft tissue keeping the arm in hanging and extended position at the side of the body, then the reading was taken to the nearest 0.1 $\mathrm{cm}$. Severe malnutrition is defined when MUAC is less than $115 \mathrm{~mm}$. Severe wasted is defined when weight for height $\mathrm{Z}$ score <-3 SD. Severe stunted is defined height for age $Z$ score <-3SD. Severe underweight is defined weight for age $Z$ score <-3 SD. Data was collected through a structured questionnaire by questioning mother and measuring height, weight and MUAC. After completion of data collection all the data were compiled, tabulated, recorded, processed and edited to reduce the errors and analyzed with the help of SPSS
(Statistical package for social science) windows programs 21.

\section{RESULTS}

A total of 500 under 5 aged children were studied. In the study area, $260(52 \%)$ of the study samples were boys and 240 (48\%) were girls (Fig-1).

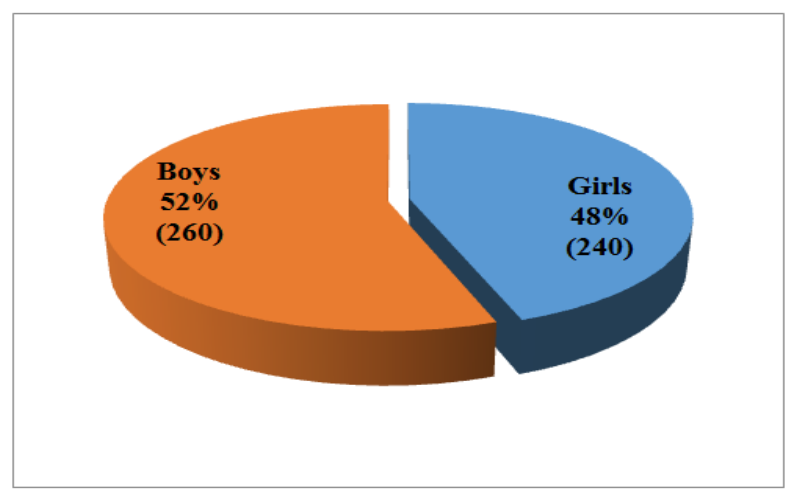

Fig.-1: Distribution of the children by gender

In slums distribution, $302(60 \%)$ children were from Agargaon slum and $198(40 \%)$ were from of Beribadh slum (Fig-2).

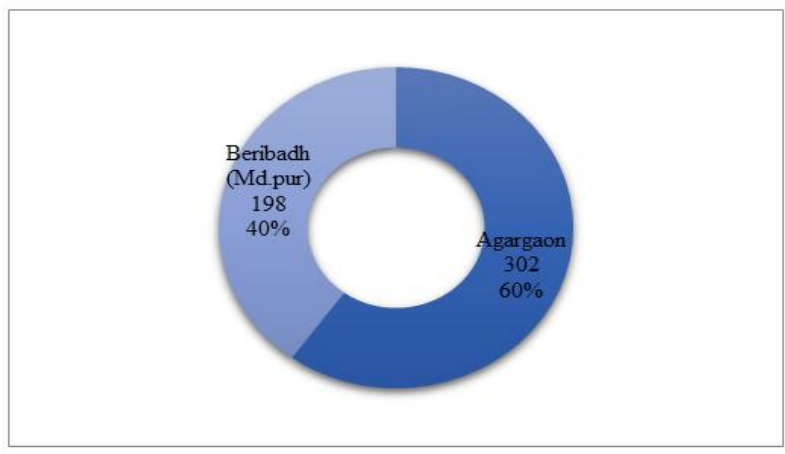

Fig-2: Distribution of children by slums

1.

2. In distribution of malnutrition, $8 \%$ were severely malnourished, $36 \%$ were mild/moderately malnourished and $56 \%$ suffers from no malnutrition (Fig-3).

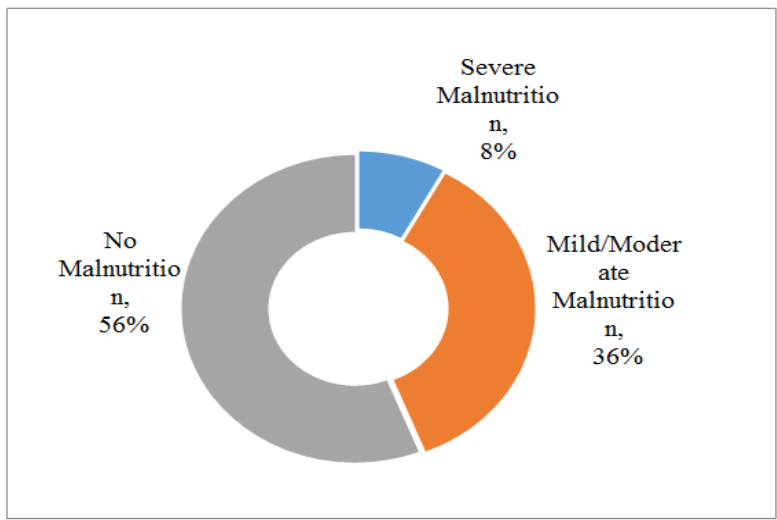

Fig-3: Distribution of the children by severity of malnutrition 
The study children were categorized into 5 groups based on age. The 6-12 months age group consisted of 90 children (male: female $=47: 43$ ). The 13 to 24 months aged group consisted of 125 children (male: female=67:58). The 25 to 36 months aged group consisted of 105 children (male: female $=52: 53$ ). The 37 to 48 months aged group consisted of 98 children (male: female=41:57). The 49 to 60 months aged group consisted of 82 children (male: female $=43: 39$ ) female (Fig-4).

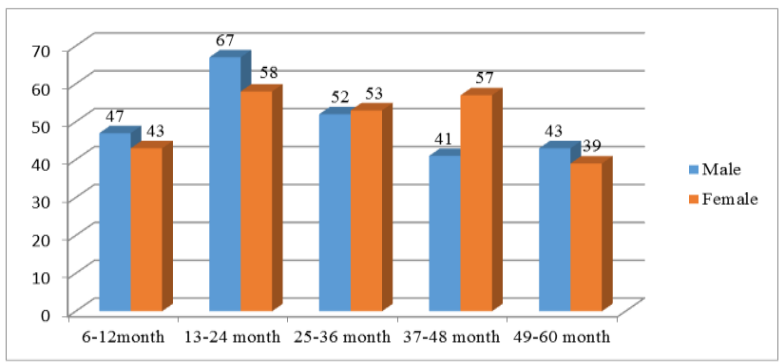

Fig-4: Distribution of children by age \& sex

Table-1: Grading of malnutrition.

\begin{tabular}{|l|l|l|l|}
\hline & Indicator & Frequency & Percentage \\
\hline MUAC* & Severe malnutrition & 40 & 08 \\
\cline { 2 - 4 } & Mild/Moderate malnutrition & 160 & 32 \\
\cline { 2 - 4 } & No Malnutrition & 300 & 60 \\
\cline { 2 - 4 } & Total & 500 & 100 \\
\hline \multirow{4}{*}{ Wasting** } & Severe wasted & 35 & 07 \\
\cline { 2 - 4 } & Mild/moderate wasted & 95 & 19 \\
\cline { 2 - 4 } & Not wasted & 370 & 74 \\
\cline { 2 - 4 } & Total & 500 & 100 \\
\hline Stunting*** & Severe stunted & 25 & 05 \\
\cline { 2 - 4 } & Mild/moderate stunted & 195 & 39 \\
\cline { 2 - 4 } & Not stunted & 280 & 56 \\
\cline { 2 - 4 } & Total & 500 & 100 \\
\hline Underweight***** & Severe under weight & 22 & 04 \\
\cline { 2 - 4 } & Mild/moderate under weight & 190 & 38 \\
\cline { 2 - 4 } & Not under weight & 288 & 58 \\
\cline { 2 - 4 } & Total & 500 & 100 \\
\hline
\end{tabular}

*MUAC -mid upper arm circumference classification, ** Weight for height $\mathrm{Z}$ score, *** Height for age $\mathrm{Z}$ score, $* * * *$ Weight for age $\mathrm{Z}$ score.

Table-1 According to MUAC classification, $08 \%$ of study children were severely malnourished, $32 \%$ mild/moderately malnourished and $60 \%$ had no malnutrition. According to weight for Height Z-score, it was found that $07 \%$ of children were severely wasted, $19 \%$ were mild/moderately wasted and $74 \%$ were not wasted. According to Height for Age Z-score, it was found that $05 \%$ of children were severely stunted, $39 \%$ of children mild/moderately stunted and $56 \%$ children were not stunted. According to Weight for Age Z-score, it was found that $04 \%$ of the study children were severely underweight, $38 \%$ children were mild/moderately stunted and $58 \%$ were not under weight

\section{DISCUSSION}

This descriptive cross sectional study was conducted with a view to determine the nutritional status of under five children of Agargaon and Beribadh slums. Children are considered as the leader of tomorrow. But they are the most victimized group of society regrettably. Chaudhary and Agrawal's [7] community based cross-sectional study was conducted in year 2016 to 2017 in a slum area of Jaipur city, Rajasthan they reported the prevalence of wasting, stunting and underweight was 10.5, 43.0 and $35.75 \%$.Gebre et al., [8] assessed a community-based cross-sectional study on 840 children aged 6-59 months to assess the prevalence of malnutrition and associated factors among under-five children in pastoral communities of Northeast Ethiopia, the study found the prevalence of wasting, stunting, and underweight was 16.2, 43.1 and 24.8\%, respectively. Dasgupta et al., [9] assessed anthropometric indices on 100 under-5 children and found prevalence of malnutrition were $42 \%$ (underweight), 30\% (wasting), $28 \%$ (stunting), and $48 \%$ (under nutrition), respectively. Zaman SU et al., [10] conducted a study on malnutrition on children of 18 months. The prevalence of underweight, stunting and wasting was $24 \%, 36 \%$ and $8 \%$ respectively. Popat et al., [11] conducted a cross sectional study and found prevalence of underweight, stunting and wasting was $32.4 \%, 46.1 \%$ and $17.2 \%$ respectively. Mamulwar et al., [12] conducted a study on malnutrition. The prevalence of underweight was $34.3 \%$, stunting was $58.7 \%$ and wasting was $16.9 \%$.The study considered with the National Center for health Statistics (NCHS) of USA standard for classification of malnutrition. According to Statistical Pocket Book of Bangladesh2004 [13], the male and female ratio was 51.2\% and $48.0 \%$, which was almost similar to male and female ratio of the present study. But in the study of Yasmeen $\mathrm{S}$ [14], conducted in Bangladesh male and female ratio found $44 \%$ and $56 \%$. According to Z-scores in the 
Aynal Hoque et al; Sch J App Med Sci, Feb, 2021; 9(2): 267-270

present study19\% children were wasted (mild/moderate), $07 \%$ children were severely wasted, $39 \%$ were stunted (mild/moderate) and $05 \%$ severely stunted, 38\% underweight (mild/moderate) and $04 \%$ severely underweight. Child Nutrition SURVEY-2000 (ages 6-71 months) [15] found in their survey that 51\% of the children were moderately underweight and $13 \%$ severely underweight, $49 \%$ moderately stunted and $19 \%$ severely stunted and $12 \%$ moderately wasted and $1 \%$ severely wasted. According to Demographic and Health Survey-1990-2000 (ages 0-59 months [16, 17]. It was found that $48 \%$ of the children were moderately underweight and $13 \%$ severely underweight, 35\% moderately stunted and $08 \%$ severely and $10 \%$ moderately wasted and $1 \%$ severely wasted. In case of wasting similar findings were stated by Gebre et al., Dasgupta et al., Popat et al., Mamulwar et al., For stunting similar findings were observed by Chaudhary and Agrawal, Gebre et al., Zaman SU et al., Demographic and Health Survey-1990-2000 (ages 0-59 months), In case of underweight simillar studies were reported by Chaudhary and Agrawal, Dasgupta et al., Mamulwar et al., Child Nutrition SURVEY-2000 (ages 6-71 months), Demographic and Health Survey-19902000 (ages 0-59 months).It was observed from the study that, the nutritional status of the study children was almost similar to the national nutritional status of similar age found in different studies [10, 12-15].

\section{Conclusion}

The nutritional status of children in slums of Dhaka is a sensitive indicator of health, economy and the sustainable development of Bangladesh. Children are the wealth and assets of a nation. Unless, the children are properly grown and developed they will be the future burden of the nation. To make a healthy and prosperous nation, the future generation of this country should be protected from ill health and malnutrition by strengthening nationwide nutritional support programs.

\section{REFERENCES}

1. Pryer JA, Rogers S, Rahman A. The epidemiology of good nutritional status among children from a population with a high prevalence of malnutrition. Public Health Nutrition. 2004; 7: 311-317

2. Morris LD, Pont A, Lewis SM. Use of a new Hemo Cue system for measuring hemoglobin at low concentrations. (WHO), Clinical and Laboratory Haematology. 2001; 23: 91-96.

3. Zondag AM, Nouwen JL, Voorhoeve HW. Immunization and nutritional status of under-five in rural Zambia. The Central African Journal of Medicine. 1992; 38:62-66.

4. AtalayY, Arcasoy A, Kürkçüoğlu M. Oral plasma Zinc tolerance test in patients with protein energy malnutrition. Archives of Disease in Childhood. 1989; 64:1608-1611.
5. Koerper MA, Dallman PR. Serum iron concentration and transferring saturation in the diagnosis of iron deficiency in children. Normal developmental changes. The Journal of Pediatrics. 1977; 6:870-874.

6. Soemantri AG, Pollitt E, Kim I. Iron deficiency anemia and education achievement. American Journal of Clinical Nutrition. 1985; 42:121-228.

7. Chaudhary P, Agrawal M. Malnutrition and associated factors among children below five years of age residing in slum area of Jaipur city, Rajasthan, India. Asian Journal of Clinical Nutrition. 2019; 11: 1-8.

8. Gebre A, Reddy P, Surender, Mulugeta A, Yayo S, Molla K. Prevalence of Malnutrition and Associated Factors among Under-Five Children in Pastoral Communities of Afar Regional State, Northeast Ethiopia: A Community-Based CrossSectional Study. Journal of Nutrition and Metabolism. 2019; 19:13-21.

9. Dasgupta A, Sahoo SK, Taraphadar P, Preeti PS, Biswas D, Kumar A, Sarkar I. Composite index of anthropometric failure and its important correlates: a study among under- 5 children in a slum of West Bengal, India. International Journal of Medical Science and Public Health. 2015; 4: 414-419.

10. Zaman SU, Seoty NR, Alam M, Haque R, Yasmin N. Household food insufficiency and child nutritional status in urban slum, Dhaka, Bangladesh Acta Medica International. 2015; 2:65-69.

11. Popat CN, Chaudhari AI, Mazumdar VS, Patel SV. A cross sectional study to measure the prevalence of malnutrition and factors associated with malnutrition among under five children of an urban slum of Vadodara city. Journal of Research in Medical and Dental Science. 2014; 2: 59-64.

12. Mamulwar MS, Rathod HK, Sumit J, Anjali D, Tanu B, Balkrishna L, Sudhir J, Bhawalkar JS. Nutritional status of under-five children in urban slums of Pune. International Journal of Medicine and Public Health. 2014; 4: 247-252.

13. Statistical Pocket Book of Bangladesh, Bangladesh Baureau of Statistics, Ministry of Planning, Bangladesh. 2004; 3: 363-399.

14. Yasmeen S. Nutritional status of under 5 children attending the outpatient department of paediatrics in Bangladesh Medical College, Dhaka. 1996; 38 41.

15. Child Nutrition Survey of Bangladesh 2000 . Publisher: Bangladesh Bureau of Statistics-2002.

16. Bangladesh Demographic and Health Survey 2000, NIPORT, Bangladesh.

17. Dwivedi SN, Banerjee N, Yadav OP. Malnutrition among children in an urban Indian slum and its associations. Indian Journal of Meternal and Child Health. 1992; 3:79-81. 